\title{
IDÉIAS
}

\section{Situação do servidor na era de transição}

\section{Paulo Vieira da Silva (*)}

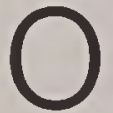

propósito deste trabalho é o de tecer algumas considerações sobe a trajetória do sistema do mérito quando a Lei que dele tratou pela primeira vez - a Lei 284 de 1936 - comemora melancolicamente o seu jubileu. Ao final, serāo apresentadas algumas proposiçōes de importáncia para a efetiva implantação do sistema do mérito no serviço público civil.

\section{A RACIONALIZAÇÃO PRE- TENDIDA}

Hả cinqüenta anos, com a lei 284 . de $28 / 10 / 36$, tomava o governo federal as primeiras medidas para a institucionalizaçào do sistema do mérito na administração federal. E para assegurar a continuidade dessas medidas foi criado o DASP (1938) c aprovado o primeiro estatuto dos funcionarios públicos civis da Uniào ( 1939). Este dispunha sobre a forma de admissão e evoluçào do funcionário em cada carreira: respectivamente concurso público e promoçào.

Essas providèncias e outras supervenientes, decorreram não apenas do espirito de emulação do poder revolucionário, instalado em 1930 . diante do governo derrubado, como também da nova filosofia intervencionista que trazia em seu bojo. De fato, o empenho era no sentido de queimar etapas no processo de desenvolvimento mediante o direcionamento dos investimentos do Estado. Mas o desenvolvimento e a conseqüente ação direta do Estado implicavam uma estrutura administrativa que servisse como veiculo para a implementaçào das diretrizes do go-

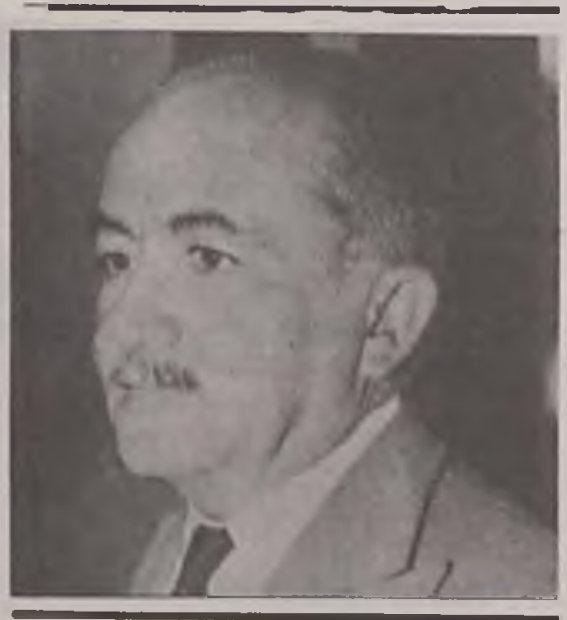

verno. Ou seja, pela primeira vez a administração pública estava sendo chamada a desempenhar um papel condizente com a sua propria natureza. Não se achava porém preparada para tanto eis que o caráter assistencial assumido ao longo do tempo a essa altura predominava e afetava toda a sua intimidade e emprestavalhe um carater de moeda no jogo da cooptação entre os meios políticos e o governo. Mas o governo nào se deu por achado e criou novas estruturas para implantar a curto e médio prazo procedimentos racionalizantes que pudessem agilizar a máquina da administração, chamando-a a conjugar o esforço que empreendia para mudar o Pais.

\section{LIMITACÕES Aं RACIONA- LIDADE DO PROCESSO}

A implementação desses mecanismos de natureza racionalizante es-

(*) Doutor (PhD) pela "University of Southern California". Prolessor da I Iniversidade de Brasília

barrou desde logo em alguns fatores desmobilizadores de natureza estrutural que limitaram a açāo de governo, como, por exemplo:

a) a circunstáncia de a administração pública vir tradicionalmente desenvolvendo uma função de natureza assistencial, pela qual em ùltima instancia o Governo admitia em seus quadros aqueles que por qualquer motivo não tivessem encontrado emprego no meio privado ou aqueles indicados por razōes politicas ou interesses pessoais. Essa prática contribuiu para mostrar que o sistema do mérito era o resultado de um diagnóstico impressionista, pois não levara em conta a realidade brasileira sempre minada pelo nepotismo e pelo clientelismo - realidade onde os quadros provisórios de nomeados sem concurso semrre foram mais expressivos quantitativa e qualitativamente;

b) a falta de um referencial técnico, em virtude do qual se pudesse elaborar não apenas um sistema de avaliação de desempenho, como também definir as faixas de remuneração do funcionalismo. Esse referencial só foi possivel com a sanção da Lei 1.711, de 1952 (o segundo estatuto dos funcionarios publicos civis). que determinava nas suas disposiçōes transitórias a criaçāo de uma comissào para elaborar um projeto de plano de classificação de cargos. $\mathrm{O}$ Congresso Nacional levou oito anos para aprovar o projeto. que se transformou na Lei no 3.780, de 1960. Essa lei, tal como aprovada, procurou conciliar os anseios de racionalizaçào do governo com a situaçào reinante de afillhadismo c resguardo de interesses pessoais ou de setores isolados do serviço publico. Mas esse plano precisava de uma 


\section{IDÉIAS}

contrapartida imprescindivel, sem a qual não seria possivel a sua implantaçào satisfatória: a especificaçāo de classes em cada um dos grupos ocupacionais em que se enfeixavam as carreiras. No entanto, foi implantado sem que elas fossem levadas em consideraçào. E durante a implantação um número muito grande de modificaçōes improvisadas mutilou-o completamente. Em 1970, com a Lei n: 5.645, o governo aprovou e comecou a implantar um outro plano de classificaçào de cargos. Este também sofreu inúmeras modificaçōes ao longo dos últimos quinze anos, algumas das quais mudaram o seu carater inicial, como por exemplo as resultantes do Decreto-lei n: 1.445, de 1976.

c) o quadro precário da nossa sociedade em termos de qualificação para o trabalho ou em termos de formação educacional, fazendo com que os postulantes a emprego público sem o crivo do concurso fossem quase sempre pessoas desqualificadas, o que levou a administração a uma situação paradoxal: tendo um numericamente expressivo efetivo de pessoal, não tinha com quem contar para o desempenho das múltiplas atividades que iam surgindo à medida que o Pais progredia e dela exigia quase sempre mais. E porque contava com quadros inchados de pessoal as verbas especificas eram literalmente diluidas para pagar salários ou vencimentos muito abaixo da média de mercado.

d) a ausência efetiva de mecanismos de avaliação de desempenho que pudessem ser implementados no servico público, os quais, do ponto de vista legal, sempre estiveram presentes no serviço público. A partir de 1937 surgiram vários, cada qual com nova feição. Mas não faziam falta. Dizia-se que era porque os chefes davam sempre conceitos excelentes para seus subordinados. Como a avaliaçào era inócua, o governo permitiu-se levar dez anos (1968-1978) sem a utilizar. E abandonnu o método das escalas gráficas para adotar o da distribuiçào forçada, que tambem nảo deu certo. Hoje, tenta utilizar novamente o método das escalas graIicas. $\mathrm{O}$ fato é que o vicio não estava nos modelos e sim na auséncia de resposta da adminisıraçào pública sobre se desejava um pessoal allamente qualificado para o exercicio de suas funcóes, e que condicoes de progresso thes daria. Como responder se a maioria esmagadora dos funcionários era admitida sem concurso público e, pior, sem se levar em conta as necessidades efetivas de admissão de pessoal e as capacitaçoes desejadas? Assim, como avaliar e para quê?

e) a incontinência legiferante, que levou tanto o poder Executivo quanto o Legislativo a incontidas modificaçōes no ordenamento juridico dos funcionários públicos sem darem tempo a um salutar processo de maturação de medidas e de situações novas, inibindo-as ou as anulando antes que pudessem produzir resultados. Para se ter uma idéia, no momento há mais de quinze mil dispositivos legais sobre o funcionalismo

\begin{tabular}{|c|}
\hline \\
O vicio estava na \\
auséncia de resposta \\
da administração \\
pública sobre se \\
desejava um pessoal \\
altamente qualificado \\
para o exercicio de \\
suas funcōes e que \\
condição de progresso \\
lhes daria. Mas como \\
responder, com as \\
distorçoes de acesso?
\end{tabular}

público em pleno vigor: a legislaçào relativa à classificaçào de cargos ja ultrapassou os duzentos atos legais, entre leis, decretos-leis, e decretos, a partir da Lei inicial, que e de 1970.

Um estudo mais aprofundado da natureza valorativa desses fatores poderá indicar com grau de certeza aceitável por que a situação do funcionalismo público chegou a tal ponto de perda de visibilidade institucional de parte do Governo.

De resto, nunca é demais lembrar que foi principalmente nos ultimos seis anos de ditadura militar - quando o Pais estava literalmente à matrocaque os funcionarios civis da administracảo federal direta e das autarquias chegaram ao ponto de quase total desestruturação como classe.
Entre os muitos sinais indicadores do desapreço que entāo prevalecia do seio do Governo Federal vale a pena mencionar os seguintes:

a) $\mathrm{O}$ abandono da politica de pessoal contida no art. 94 do DecretoLei 200/67;

b) a ausência de uma legislação que dè conseqüèncias à função de treinamento, fazendo sentir os seus efeitos imediatos nào apenas no aprimoramento do desempenho do órgào que treinou seus funcionários ou parte deles, mas também e principalmente na progressāo e ascençāo funcionais e na contrapartida salarial do servidor treinado;

c) o aviltamento da remuneraçāo dos funcionários públicos da administraçāo direta e das autarquias que, por sinal, sāo os únicos a que se aplica o Plano de Classificação de Cargos (PCC). Todos os setores interessados sabem que a situação salarial dos funcionários públicos civis da União - que sempre deixou a desejar, quando comparada com a de outras classes trabalhadoras - piorou sensivelmente a partir de 1979. De tal modo que hoje aqueles funcionarios públicos, mesmo com o reajustamento de $25 \%$, de janeiro de 1987 , recebem um quarto do que recebiam naquela época (considerados mês a mês os indices de inflação oficialmente adotada). Ninguém poderá em sã consciència alegar a crise econömica, a necessidade de baixar a inflação e outros clichês da moda, até mesmo porque o governo mostrou-se magnánimo com outros setores a ele ligados, como os servidores das estatais e os militares, atribuindo-lhes direta ou indiremente aumentos muito mais expressivos do que aqueles destinados aos funcionarios civis. Por exemplo: os servidores das estatais acabaram vencendo a camisa-de-força do Decreto-Lei 2.065; (de má memória) e conseguiram aumentos de salário fora dos limites ali estabelecidos. E os militares conseguiram transformar suas gratificaçōes (menos a de tempo de serviço) em indenizaçōes, com o que se viram isentos do imposto de renda nessa parte (o que representou um acréscimo salarial indireto da ordem de $30 \%$ em média) e além disso conseguiram a semestralidade de aumento de seus soldos em dezembro de 1983, hoje em parte superada pelo Plano Cruzado. Por que então o vencimento atual do funcionário da administração direta e das 
IDÉIAS

autarquias comuns representa apenas $25 \%$ do que ganhava em 1979? A coisa chegou a tal ponto o mero aumento do salário mínimo engolia em torno de doze referências iniciais do Plano de Classificação de Cargos. Veja-se que naqueles fatidicos seis anos o indice geral de preços e a receita federal cresceram respectivamente $300 \%$ e $400 \%$ mais que o indice de aumento dos funcionários públicos. Há qualquer política de treinamento que resista a esse desestímulo crónico? As gratificaçōes, as triangulaçoes e outros artificios que vêm surgindo aqui e ali não são uma resposta satisfatória. Desse modo se fecha o circulo vicioso: porque paga mal a administração pública atrai a mảo-de-obra mais desqualificada; os esforços de treinamento são concentradas na recuperaçào dessa mão-deobra; à falta de incentivos e estímulos, a mào-de-obra treinada evade-se para o meio empresarial privado ou público!

\section{O DILEMA ATUAL}

O vezo da administraçào inconseqüente e a perda de visibilidade quanto à necessidade de resguardo de principios sobre os quais estribar a açāo do Governo levaram a um crescimento desordenado do funcionalismo civil, e sobrecarregaram inclusive os programas de treinamento de servidores públicos. $O$ proprio DASP, nos anos setenta, contribuiu para essa exacerbação quando adotou a sistemática de simplificar as provas dos concursos publicos e compensar as deficiências dos aprovados em programas internos de treinamento logo apos a sua nomeaça. Foi a época do apogeu das firmas montadas para oferecer ao servico publico pacotes de treinamento.

Aliás, nào fosse por outros sinais indicadores de desapreço do goveno pelo funcionalismo publico, dir-se-ia que com os programas de treinamento se estava procurando suprir institucionalmente as deficiências crônicas instaladas no serviço público $\mathrm{e}$ nortear essa mão-de-obra reciclada no rumo da consecuçào dos objetivos maiores dos órgãos públicos. O treinamento, todavia, à falta de uma visảo institucional do assunto, passou a ser quase que um fim em si mesmo. Com exceçoes honrosas e facilmente identificáveis, os programas de treinamento cairam no vazio, e represen-

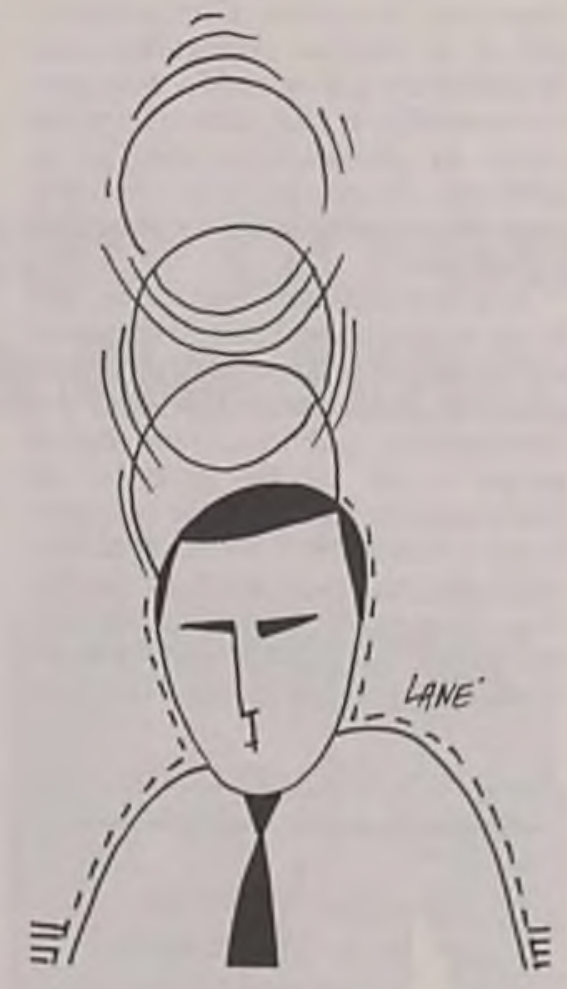

E possivel aceitar que um funcionário que volta ao serviço após um periodo de especializaçāo continue fazendo as mesmas tarefas de que era encarregado antes dessa nova experiência, no mesmo nivel e com o mesmo salário?

\section{PERSPECTIVAS FUTURAS}

O principio da parcimónia, em ciência, assegura que o que é constante no passado é provável no futuro. $\mathrm{E}$ a continuar o estado de coisas reinante quanto aos funcionários públicos civis, as perspectivas são sobretudo sombrias e desnorteantes.

O Brasil corre o sério risco de chegar ao fim deste século sem uma definição institucional sobre os funcionários públicos civis. Isso é tanto mais grave quanto se atenta para a circunstancia de que os funcionários públicos civis são o único recurso humano com que legitimamente conia a administraçào federal para a consecucāo de seus objetivos permanentes.

Apesar de o Governo ainda continuar tergiversando sobre a formulaçào e implementação de uma politica que valorize essa classe, a análise da situação e de suas conseqüèncias nefastas em outros pontos da estrutura instalada do País pode contribuir para criar zonas de sensibilidade capazes de favorecer um reexame do quadro atual e até mesmo levar a um pacto entre os poderes constituidos quanto aos rumos a serem seguidos.

Com esse espirito seria o caso de considerar algumas proposiçoes de importância estratégica na agilização do servico público pelo aprimoramento da capacitação do seu funcionalismo, e meditar sobre a possibilidade de sua inclusão nos institutos legais que configurarão o ordenamento juridico da classe em futuro próximo:

taram uma perda enorme de recursos públicos. Talvez essa situaçào tivesse ocorrido pela inexistència de mecanismos de controle daquilo que se faz comparado com aquilo que se pretendia fazer. pois ex exatamente ai que está em jogo a competència do funcionário. A falta de mecanismos de avaliaçào de desempenho. segundo padrōes previamente estabelecidos, como identificar necessidades de treinamento? E, como um corolário, quais os resultados do treinamento?
1) a remuneração do servidor público deve ser fixada segundo os salários de mercado conjugadamente com outros fatores do interesse da administração, e corrigida sempre que for necessário resguardar a sua integridade:

2) a evolução do funcionário deve ser favorecida. no serviço, segundo critérios técnicos claramente identificados (classifica- 


\section{IDÉIAS}

çào e avaliaçào de cargos, sistemas de avaliação de desempenho);

3) os sistemas de promoçào (ascensão e progressão funcionais) devem necessariamente levar em conta os programas de treinamento e especialização a que o funcionário se tenha submetido para o desempenho de funções do interesse do órgảo onde trabalha;

4) os programas de treinamento devem levar em consideração as atividades dos órgãos públicos e as respectivas funçōes atribuidas aos funcionários neles lotados, bem como os deveres destes perante o público e as instituiçōes;

$5)$ os cargos de chefia, com exceçōes criteriosamente estudadas, devem ser destinados a funcionários de carreira;

6) além do treinamento para o melhor desempenho de suas funções, o funcionário deve ser treinado para o eventual exercicio de funções mais complexas e de maior responsabilidade:

7) urge instalar o contencioso administrativo;

8) urge estimular o espirito classista do funcionário publico, dandolhe condiçōes de vocalizar os seus interesses mais legitimos e lutar institucionalmente por eles.

9) urge modificar o ordenamento juridico dos funcionários públicos civis, impondo à sua lei de criação um prazo de carência de no minimo cinco anos, durante o qual nem o Executivo nem o Legislativo modificariam qualquer um dos seus dispositivos; após esse prazo o ordenamento poderia sofrer as modificaçōes ditadas pela necessidade de seu progressivo ajustamento à realidade superveniente.

10) urge modificar a Constituição Federal, eliminando, do artigo 57 e incisos, a exclusividade de iniciativa do Presidente da Republica para leis que se refiram ao ordenamento juridico dos funcionários públicos - pois esta representa uma mordaça ao Poder Legislativo que inibe a sua legitima capacidade de representar e atender aos anseios dos mais diversos setores da sociedade brasileira e - por que não? dos funcionarios públicos civis!

\section{Mais produtividade pública é possível}

\section{Marianno Philgret(*)}

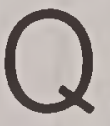

uando, com os mesmos recursos disponiveis, conseguimos aumentar o volume de produção, está configurada a elevação da produtividade. Esta, em sintese, é a relaçāo entre o que se produz e os insumos empregados.

Inúmeras formas são usadas para a determinação da produtividade, podendo-se lembrar, como exemplo, o relacionamento do número de toneladas de qualquer produto agricola obtido por hectare plantado.

Na iniciativa privada é comum aos empresários buscarem, valendo-se de métodos empiricos, elevar a produção pelo melhor emprego dos recursos de que dispōem. Mesmo sem aplicarem tecnologia mais avançada ou novas máquinas, conseguem reduzir os custos e/ou aumentar o nivel da produção, mantendo o numero de empregados, horas trabalhadas etc., ou seja, apenas aplicando outros processos produtivos, ou até pela motivação dos subordinados.

As empresas de porte, por disporem de recursos financeiros e maior conhecimento por parte de seus dirigentes, estabelecem condiçōes favoráveis para a busca permanente de mais alto nivel de produtividade. Grandes organizações mantêm departamentos que se dedicam unicamente à pesquisa no campo da racionalização do trabalho e adoção de tecnologia sofisticada. Não raro, utilizam testes psicológicos e cursos internos, mantendo altos padrôes de rendimento das equipes.

Pode-se dizer que na iniciativa privada e eficiència se confunde com a eficácia. A incessante procura de elevar a produtividade e aprimorar a qualidade dos produtos ou serviços e

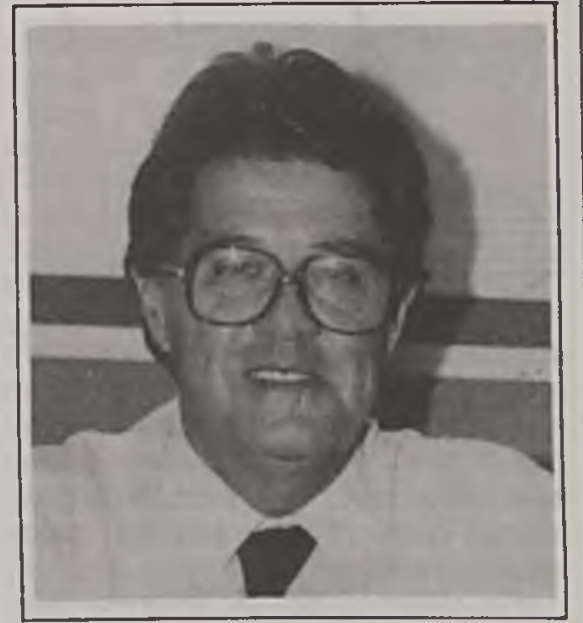

da mais alta importância na garantia do futuro da empresa. Ela é tida como eficiente devido ao adequado processo produtivo, e eficaz por bem atender às solicitaçōes do mercado.

No entanto, se nos voltarmos para a máquina administrativa governamental, encontramos distorções lamentaveis, tão bem enfatizadas em recente Exposição de Motivos dos Ministros do Grupo Executivo para a Reforma Administrativa (GERAP) ao Presidente da República. Os termos, às vezes acres, descrevem a situação caótica em que nos encontramos.

É pfovável que a diferença predominante entre o setor público e o privado esteja estreitamente ligada ao espirito empresarial. Salvo raras exceçōes, a grande maioria dos órgãos administrativos, nos três niveis do governo: federal, estadual e municipal, é dirigida sem a observância de principios básicos que devem reger as 